\title{
Cervical Carcinoma in Early Pregnancy - Successful Birth by Caesarean Section Followed by Radical Hysterectomy
}

\author{
Zervixkarzinom in der Frühschwangerschaft - \\ Erfolgreiche Geburt per Sectio mit anschließender radikaler Hysterektomie
}

Authors

Affiliation
K. Schreiber, S. Rothe, M. Untch

Gynaecology and Obstetrics, Helios Klinikum Berlin-Buch, Berlin

\begin{abstract}
Key words
- cervical carcinoma

- pregnancy

- radical hysterectomy

- Caesarean section

Schlüsselwörter

- Zervixkarzinom

- Schwangerschaft

- radikale Hysterektomie

- Kaiserschnitt
\end{abstract}

Deutschsprachige Zusatzinformationen online abrufbar unter: www.thieme-connect.de/ ejournals/toc/gebfra

\section{received $\quad 6.11 .2013$ \\ revised $\quad 3.1 .2014$ \\ accepted 9.1.2014}

Bibliography

DOI http://dx.doi.org/

10.1055/s-0033-1360329

Geburtsh Frauenheilk 2014; 74 : 284-287 @ Georg Thieme Verlag KG Stuttgart · New York . ISSN 0016-5751

\section{Correspondence}

\section{Kathi Schreiber}

Helios Klinikum Berlin Buch Gynaecology and Obstetrics Schwanebecker Chausse 50 13125 Berlin

kathi.schreiber@

helios-kliniken.de

\section{Abstract \\ $\nabla$}

A cervical carcinoma was diagnosed in a 32-yearold patient in the 17th week of her pregnancy. The histological confirmation revealed a well-differentiated squamous cell carcinoma. It was a clinical stage Ib1 tumour, without enlarged lymph nodes according to the image. After a staging MRI, intensive education of the patient and case discussion at the interdisciplinary tumour board as well as consultation with the neonatologist, it was agreed to prolong the pregnancy under close monitoring. The carcinoma was confined to the cervix in the further course of the pregnancy. The elective delivery was planned after 32 weeks of gestation. The primary Caesarean section followed by radical hysterectomy Piver II were carried out without complications. After regular postoperative progression of the mother, brachytherapy was performed at the appropriate time. The premature newborn was under neonatal care and exhibited good postnatal adaptation. Mother and child were discharged in good health.

\section{Introduction}

In recent years, an increase has been observed in the number of incidences of carcinomas during pregnancy [1]. The cervical carcinoma is the most common solid carcinoma during pregnancy, with an estimated occurrence of 1-2 cases per 120010000 pregnancies. Cytology is part of prenatal care in Germany [2,3]. Approx. 3\% of all newly diagnosed cervical cancers affect pregnant women [4]. The simultaneous occurrence of pregnancy and a cervical carcinoma presents a dilemma for the affected couples, doctors and relatives, and it requires special expertise to advise and treat these patients, especially if they wish to go on with the pregnancy [5-7]. The ideal setting in this

\section{Zusammenfassung}

$\nabla$

Bei einer 32-jährigen Patientin wurde in der 17. Schwangerschaftswoche ein Zervixkarzinom diagnostiziert. Die histologische Sicherung ergab ein gut differenziertes Plattenepithelkarzinom. Es handelt sich um ein klinisches Tumorstadium Ib1, bildgebend ohne vergrößerte Lymphknoten. Nach Staging-MRT, intensiver Aufklärung der Patientin und Falldiskussion im interdisziplinären Tumorboard sowie Absprache mit den Neonatologen wurde die Prolongation der Schwangerschaft unter engmaschiger Kontrolle vereinbart. Das Karzinom blieb im weiteren Schwangerschaftsverlauf auf die Zervix beschränkt. Die elektive Entbindung wurde nach 32 SSW geplant. Die primäre Sectio caesarea mit anschließender radikaler Hysterektomie nach Piver II verlief ohne Komplikationen. Bei regelrechtem postoperativem Verlauf der Mutter wurde zeitgerecht die Brachytherapie durchgeführt. Das prämature Neugeborene wurde bei guter postnataler Adaptation neonatologisch betreut. Mutter und Kind konnten gesund nach Hause entlassen werden.

case would be a clinic with a perinatal centre as well as a gynaecologic oncology centre. The vast majority of cervical carcinomas (approx. 70\%) are diagnosed in Stage I, which means that they are more frequently discovered at an operable stage than is the case outside of pregnancy $[4,8]$. Cervical carcinoma treatment is well-defined outside of pregnancy, but there are only limited recommendations for an approach to treating cervical carcinomas in pregnant women. In Germany, there are currently no guidelines on how to proceed in pregnant women with a cervical carcinoma (p3 Diagnostics Guideline and Treatment for Cervical Carcinomas is being worked on). Neither do large randomised studies exist about this topic; most mentions in references concern indi- 


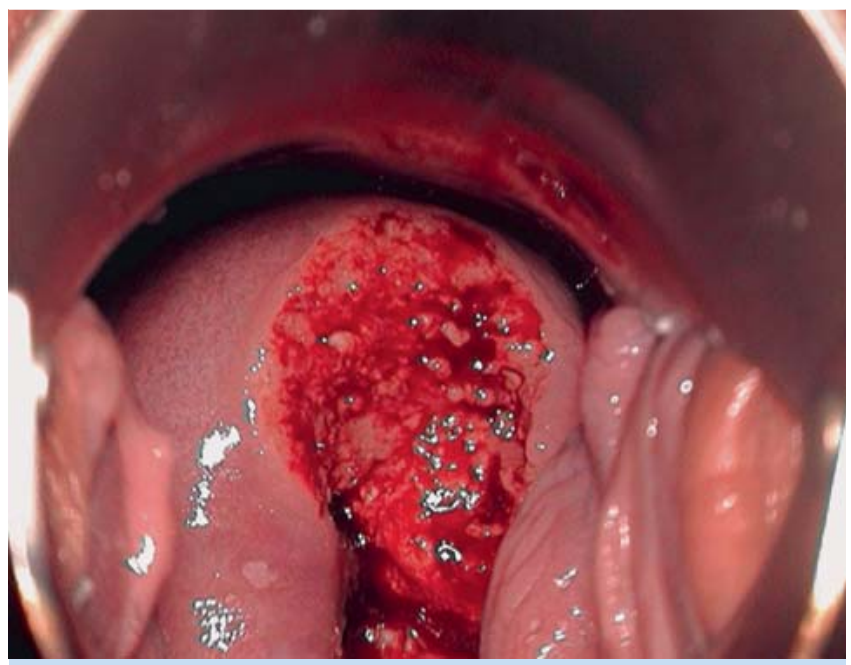

Fig. 1 Colposcopy week 16 of the pregnancy with ulcer on the anterior cervical lip with peripheral ridge.

vidual cases or retrospective overviews $[6,7,9,10]$. The approach during pregnancy depends on the gestational age, tumour stage, risk factors such as lymph node infection, and the patient's wishes. To evaluate the lymph nodes, a staging laparoscopy is considered in addition to the native MRI scan in the first trimester of pregnancy. In this report, we describe the case of a patient who was diagnosed with a cervical carcinoma in early pregnancy and subsequently had a Caesarean section followed by a radical hysterectomy (Piver II) in week 33 of her pregnancy.

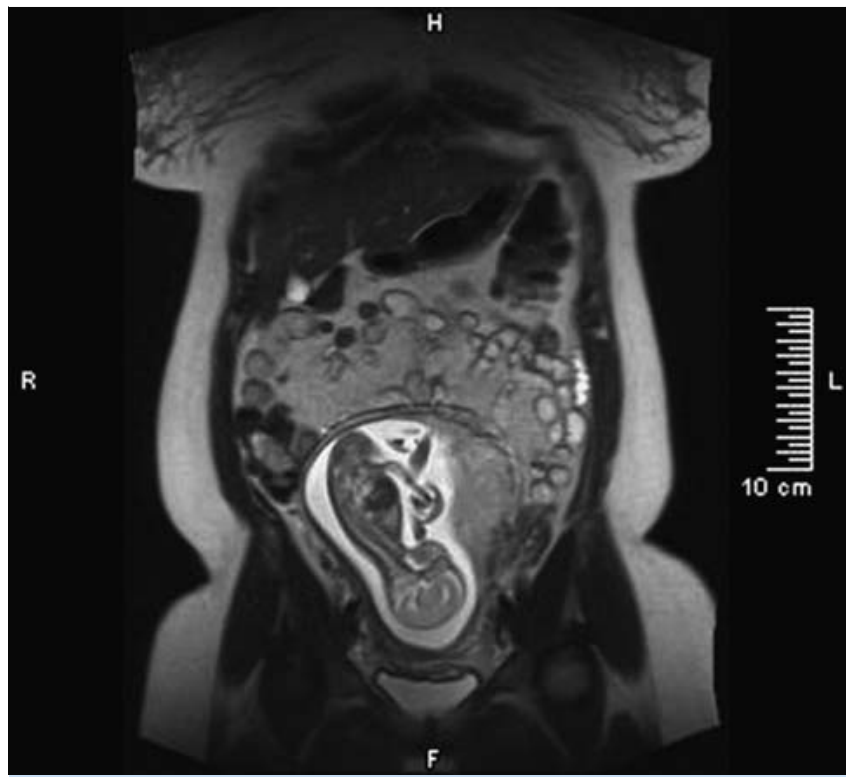

Fig. 2 MRI (week 17 of pregnancy). No space-occupying lesion in the cervical cavity. No indication of tumour formation transgressing the cervical wall. Unremarkable appendages. Lymph nodes in the pelvis without pathological lymph node enlargement.

\section{Case Presentation}

The treating gynaecologist of the 32-year-old patient made a suspect cytological finding (Pap IVa) in week 15 of the pregnancy. It was subsequently presented to the dysplasia clinic ( $\bullet$ Fig. 1). A targeted biopsy was taken from an ulcer on the anterior cervical lip in weeks $16+6$ of the pregnancy. It showed a well-differentiated squamous cell carcinoma on the floor of a high-grade cervical intra-epithelial neoplasia (CIN III). It was a clinical tumour stage Ib1. The patient was informed in detail about the diagnosis and possible treatment options. Both a termination of pregnancy followed by radical surgery as well as a continuation of the pregnancy were discussed. An MRI scan was performed for staging, showing no evidence of pathological lymph nodes and no evidence of metastasis ( $\mathbf{O}$ Figs. 2 and $\mathbf{3}$ ). At a subsequent consultation, the affected couple proved to be determined to continue the pregnancy. The recommended staging laparoscopy with lymphadenectomy and neoadjuvant chemotherapy were both declined by the patient. Radiotherapy was not recommended due to the desire to continue the pregnancy.

The tumour board considered the findings and the patient's wishes, and the prolongation of the pregnancy under close monitoring as well as elective Caesarean section after 32 weeks of gestation followed by radical hysterectomy and pelvic lymphadenectomy were planned.

During the course of the pregnancy, the carcinoma was limited to the cervix in the 4-weekly colposcopies. The performed MRI examinations ( 0 Figs. 4 and $\mathbf{5}$ ) showed no progression of findings, the pelvin and para-aortic lymph nodes were also still unremarkable in imaging. Bladder and intestine showed no tumour involvement.

Simultaneously, the detailed foetal diagnosis in the 22nd week of the pregnancy showed unremarkable foetal findings, lung maturation was performed in week 24 of the pregnancy with $2 \times 12 \mathrm{mg}$ betamethasone.

In week $32+5$ of the pregnancy, the primary Caesarean section was performed at the III gravida II para with longitudinal laparot-

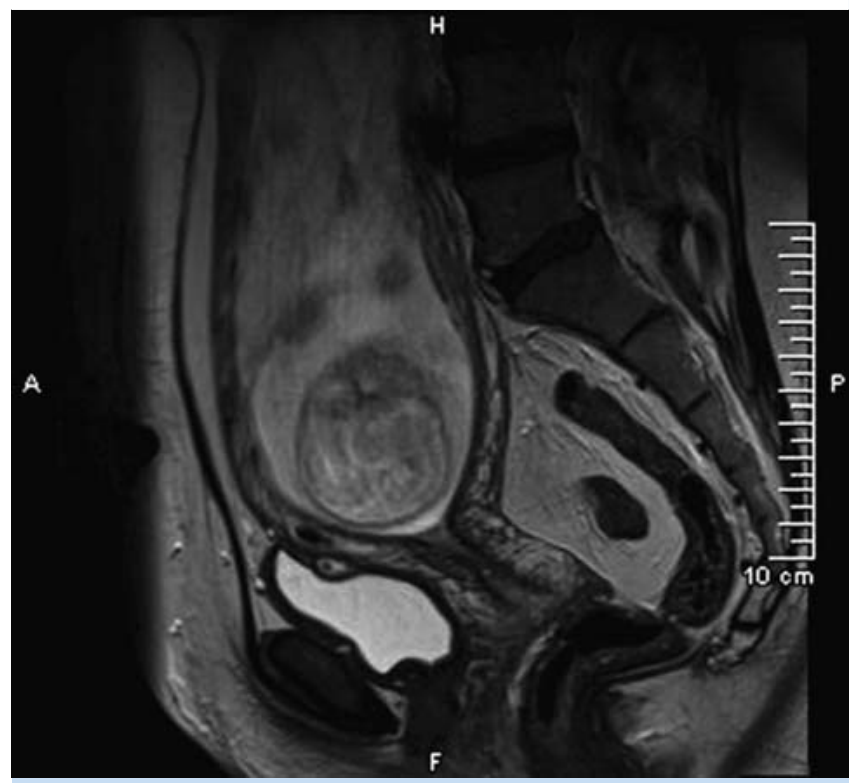

Fig. 3 MRI (week 17 of pregnancy). 


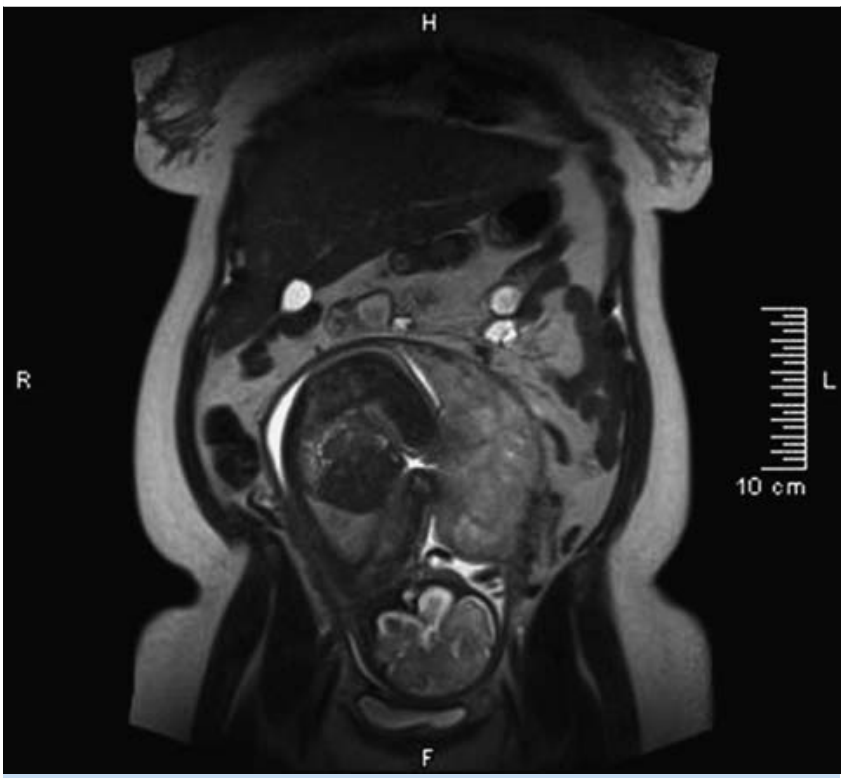

Fig. 4 MRI (week 31 of pregnancy). Foetus in the second occipito-anterior position. Placenta on the left. No indication of progressive mass in the area of the cervix uteri. Appendages free. Detection of two max. $3 \mathrm{~mm}$ diameter large lymph nodes in the pelvis.

omy and isthmus corporal uterine longitudinal section, with normal child development from I. cephalic and late umbilical cord. After manual removal of the placenta, the uterotomy was closed. The lively premature girl was treated by the waiting neonatologists, with good overall adaptation, only CPAP respiratory support was necessary (w, 1980 g, 46 cm, Apgar 8/8/8, NapH 7.33).

The subsequent Piver II surgery was carried out without complications. After exploration of the abdomen, the hysterectomy was performed with parametric resection and vaginal cuff and pelvic lymphadenectomy. Ovariopexy was performed on both sides for the protection of the ovaries from potential adjuvant radiotherapy. The frozen section examination of the iliac lymph nodes showed no tumour involvement, giving no indication for a paraaortic lymphadenectomy. With a blood loss of approx. $1000 \mathrm{ml}$, 2 erythrocyte concentrates and coagulation factors were administered. The operation was well tolerated by the patient. After a short stay in the Intermediate Care Station, the patient was moved to the postnatal station with a normal postoperative course. In particular, no bladder voiding disorder occurred. Mother and child were discharged in good health on the 8th and 16 th postnatal days respectively.

In summary, the tumour stage was: pT1b1 pN0 (0/47) L1 (small foci), V0 R0 G1. The histological examination revealed a highly differentiated invasive squamous cell carcinoma of the cervix with a longitudinal extent of $26 \mathrm{~mm}$ and depth of infiltration of $3 \mathrm{~mm}$. Small foci lymphatic invasion in tumour vicinity. The invasive carcinoma was within $8 \mathrm{~mm}$ of the vaginal surgical margins of the anterior lip of the cervix.

In the postoperative case discussion, a decision was made for brachytherapy due to the small foci lymphatic invasion. After completion of wound healing, the patient received a total of $30 \mathrm{~Gy}$ in 6 fractions. At the end of radiation, no discomfort was noted beyond a first degree mucous membrane erythema. The follow-up treatment is done, the patient is in after-care and without recurrence and free of metastasis.

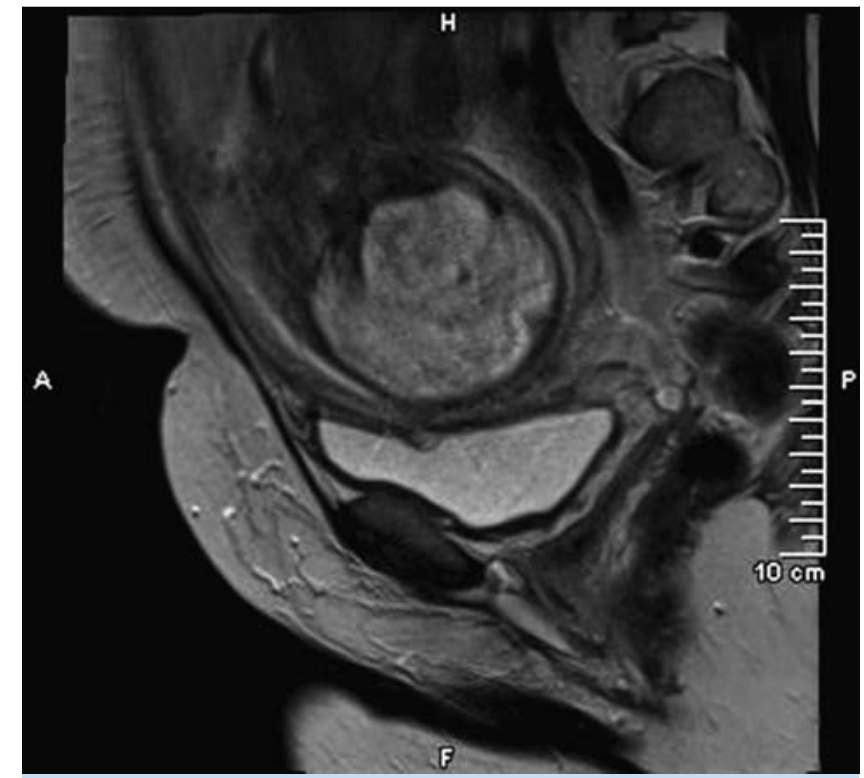

Fig. 5 MRI (week 31 of pregnancy).

\section{Discussion}

$\nabla$

For cervical cancer before the 16th week of pregnancy, immediate oncological therapy of the patient is initiated after termination of the pregnancy. If the diagnosis occurs after the 16th20th week of pregnancy, under certain conditions a treatment can be delayed until foetal viability, without causing a worse oncological outcome, as seen in data from individual case reports and retrospective analyses $[11,12]$. This is particularly true if no lymph node metastases were detected. But especially in patients before the 20th week of pregnancy, it must be considered that early cervical carcinomas can also lead to lymph node metastasis or that rapid tumour progression can occur [13]. The presented case illustrates that a pregnancy can continue with a cervical carcinoma in clinical tumour stage Ib1, without leading to poorer oncological outcomes. However, close monitoring of the patient is necessary, consisting of colposcopic control, ultrasound and possibly MRI, due to the pregnancy. The MRI can be used several times [14]. Laparoscopy with lymphadenectomy should be performed for histological confirmation. This can be performed up to the 20th week of pregnancy and represents the ideal staging for the cervical carcinoma FIGO Ib1 in pregnancy [15]. If the findings do not progress and a lymph node infection can be ruled out, pregnancy continuation is possible. Besides the tumour stage, the wishes of the affected patient and her partner are critical to the individual approach. There are several reports on neoadjuvant chemotherapy with cisplatin [16-18]. Both staging laparoscopy and neoadjuvant chemotherapy were excluded in this case because the patient vehemently refused both treatment options. There are fewer cases in literature for radical hysterectomy in combination with a Caesarean section [19]. The radical hysterectomy is the standard surgery for the treatment of stages IB and IIA. However, the high morbidity and mortality rates, especially for the surgery in combination with Caesarean section or in the postpartum period, must be taken into account. After diagnosis, 
the therapy should be planned jointly with the affected couple. In doing so, the tumour stage, gestational age, and in particular the patient's wishes are to be taken into account. Prevention of iatrogenic prematurity is an important part of the treatment strategy [20]. The Caesarean section is to be regarded as a mode of delivery of first choice in case of an invasive carcinoma in pregnancy [21]. A vaginal birth is not an option due to the unpredictable, high risk of bleeding and the risk of metastasis in case of perineal tear or episiotomy. The optimal timing of delivery should also be based on the foetal maturity and the associated iatrogenic prematurity (> 32 weeks) [16]. In this case, it was possible to perform the Caesarean section at the end of the 33rd week of pregnancy, and lung maturity treatment was concluded. At delivery the premature baby was adequately developed and presented good postnatal adaptation without complications; only CPAP respiratory support was required for a few days. The high risk of surgery was calculated thanks to intensive preparation; maternal complications did not occur.

\section{Summary}

$\nabla$

The present case shows that in a patient with a cervical carcinoma FIGO Ib1 in early pregnancy, not only can the pregnancy be prolonged until the completion of lung maturity, but that it can also remain without negative impact on the oncological outcome. In our case, it was possible to perform a Caesarean section followed by Piver II without complications for mother or child. However, treatment decisions need to be discussed thoroughly with the patient and also interdisciplinarily without fail. There must be close monitoring of pregnancy and tumour status in order not to jeopardize both the pregnancy and the oncological outcome. This requires optimal conditions with appropriate structural and personnel infrastructure.

\section{Conflict of Interest}

\section{$\nabla$}

None.

\section{References}

1 Sadler L, Sykes P. How little is known about cervical cancer in pregnancy? Ann Oncol 2005; 16: 341-343

2 Partridge EE, Abu-Rustum N, Campos S et al.; National Comprehensive Cancer Network. Cervical cancer screening. J Natl Compr Canc Netw 2008; 6: 58-82

3 Weisz B, Schiff E, Lishner M. Cancer in pregnancy: maternal and fetal implications. Hum Reprod Update 2001; 7: 384-393

4 Jones WB, Shingleton HM, Russell A et al. Cervical carcinoma and pregnancy. A national patterns of care study of the American College of Surgeons. Cancer 1996; 77: 1479-1488

5 Amant F, Van Calsteren K, Halaska MJ et al. Gynecologic cancers in pregnancy: guidelines of an international consensus meeting. Int J Gynecol Cancer 2009; 19 (Suppl. 1): S1-S12

6 Strauss A, Strauss C, Hilpert F et al. Gynäkologische Krebserkrankungen während der Schwangerschaft. Gynäkologe 2011; 44: 725-734

7 Strauss A. Guter Hoffnung und vom Tode bedroht - krebskrank und schwanger. Speculum 2010; 28: 8-19

8 Sood AK, Sorosky JI. Invasive cervical cancer complicating pregnancy. How to manage the dilemma. Obstet Gynecol Clin North Am 1998; 25: 343-352

9 Lee JM, Lee KB, Kim YT et al. Cervical cancer associated with pregnancy: results of a multicenter retrospective Korean study (KGOG-1006). Am J Obstet Gynecol 2008; 198: 92.e1-92.e6

10 Amant F, Brepoels L, Halaska MJ et al. Gynaecologic cancer complicating pregnancy: an overview. Best Pract Res Clin Obstet Gynaecol 2010; 24: 61-79

11 Zemlickis D, Lishner M, Degendorfer $P$ et al. Maternal and fetal outcome after invasive cervical cancer in pregnancy. J Clin Oncol 1991; 9: 19561961

12 Goncalves CV et al. Diagnosis and treatment of cervical cancer during pregnancy. Sao Paulo Med J 2009; 127: 359-365

13 Benhaim Y, Pautier P, Bensaid C et al. Neoadjuvant chemotherapy for advanced stage cervical cancer in a pregnant patient: report of one case with rapid tumor progression. Eur J Obstet Gynecol Reprod Biol 2008; 136: 267-268

14 Morice $P$ et al. French recommendations on the management of invasive cervical cancer during pregnancy. Int J Gynecol Cancer 2009; 19: $1638-1641$

15 Hoellen F, Dietrich $K$, Beyer DA et al. Zervixkarzinom in der Schwangerschaft. Der Gynäkologe 2012; 12: 939-944

16 Caluwaerts S, van Calsteren K, Mertens L et al. Neoadjuvant chemotherapy followed by radical hysterectomy for invasive cervical cancer diagnosed during pregnancy: report of a case and review of the literature. Int J Gynecol Cancer 2006; 16: 905-908

17 Bader AA, Petru E, Winter R. Long-term follow-up after neoadjuvant chemotherapy for high-risk cervical cancer during pregnancy. Gynecol Oncol 2007; 105: 269-272

18 Karam A, Feldman N, Holschneider CH. Neoadjuvant cisplatin and radical cesarean hysterectomy for cervical cancer in pregnancy. Nat Clin Pract Oncol 2007; 4: 375-380

19 Watanabe Y, Tsuritani M, Kataoka T et al. Radical hysterectomy for invasive cervical cancer during pregnancy: a retrospective analysis of a single institution experience. Eur J Gynaecol Oncol 2009; 30: 79-81

20 Van Calsteren $K$ et al. Cancer during pregnancy: an analysis of 215 patients emphasizing the obstetrical and the neonatal outcomes. J Clin Oncol 2010; 28: 683-689

21 Iams JD, Romero R, Culhane JF et al. Primary, secondary, and tertiary interventions to reduce the morbidity and mortality of preterm birth. Lancet 2008; 371: 164-175 